\title{
The COVID-19 Pandemic and Levels of Physical Activity in the Last Trimester, Life Satisfaction and Perceived Stress in Late Pregnancy and in the Early Puerperium
}

\author{
Daria Kołomańska-Bogucka ${ }^{1}$ (D), Agnieszka Micek ${ }^{2}$ (D) and Agnieszka I. Mazur-Bialy ${ }^{1, *(D)}$ \\ 1 Department of Biomechanics and Kinesiology, Faculty of Health Science, Jagiellonian University Medical \\ College, Skawińska 8, 31-066 Krakow, Poland; daria.kolomanska@doctoral.uj.edu.pl \\ 2 Faculty of Health Science, Institute of Nursing and Midwifery, Jagiellonian University Medical College, \\ Kopernika 25, 31-501 Krakow, Poland; agnieszka.micek@uj.edu.pl \\ * Correspondence: agnieszka.mazur@uj.edu.pl; Tel.: +48-012-421-9351
}

\section{check for}

updates

Citation: Kołomańska-Bogucka, D.;

Micek, A.; Mazur-Bialy, A.I. The

COVID-19 Pandemic and Levels of

Physical Activity in the Last

Trimester, Life Satisfaction and

Perceived Stress in Late Pregnancy

and in the Early Puerperium. Int. J.

Environ. Res. Public Health 2022, 19,

3066. https://doi.org/10.3390/

ijerph19053066

Academic Editor: Yuka Kotozaki

Received: 25 December 2021

Accepted: 1 March 2022

Published: 5 March 2022

Publisher's Note: MDPI stays neutral with regard to jurisdictional claims in published maps and institutional affiliations.

Copyright: (C) 2022 by the authors. Licensee MDPI, Basel, Switzerland. This article is an open access article distributed under the terms and conditions of the Creative Commons Attribution (CC BY) license (https:// creativecommons.org/licenses/by/ $4.0 /)$.

\begin{abstract}
Background: The aim of this study was to determine the impact of the COVID-19 pandemic on the levels of physical activity during the third trimester of pregnancy, life satisfaction and stress in women in late pregnancy and early postpartum. Methods: The study was conducted among 740 patients of maternity wards in Cracow hospitals on days 1-8 postpartum. Patients who were surveyed before the pandemic (December 2019-March 2020) were included in the prepandemic group (PPan: $n=252$ ). The second group of women (COVID 1 group, Cov1: $n=262$ ) was examined in the early stages of the pandemic (May-September 2020). In turn, participants who were surveyed during the population vaccination campaign (June-September 2021) were qualified to the COVID 2 group (Cov2: $n=226$ ). The research tools used were the original questionnaire in addition to standardized questionnaires assessing physical activity in the last trimester of pregnancy (the Pregnancy Physical Activity Questionnaire); previous life satisfaction (the Satisfaction with Life Scale); and stress levels during the last month (the Perceived Stress Scale). Results: During the pandemic, women reduced the level of energy spent on total physical activity; nevertheless, statistically significant differences were found only between the PPan and Cov2 groups $(p=0.001)$. At the early stages of the pandemic, patients significantly reduced mobility activities (Cov1 vs. PPan: $p<0.001$; Cov1 vs. Cov2: $p=0.007$ ), while late in the pandemic they spent less energy on household activities (Cov2 vs. PPan: $p=0.002$, Cov2 vs. Cov1: $p=0.002$ ). There were no differences in the levels of stress and life satisfaction. Conclusions: The COVID-19 pandemic impacted the level of physical activity; however, it did not change levels of perceived stress and life satisfaction in women in late-stage pregnancy and in the early puerperium.
\end{abstract}

Keywords: COVID-19; SARS-CoV-2; pregnant women; pregnancy; puerperium; physical activity; life satisfaction; stress; anxiety

\section{Introduction}

Pregnancy is a special period during women's lives, accompanied by changes, both biological and physiological, as well as psychological and social. These changes may develop from the beginning of pregnancy and even last until the postpartum period [1] Nausea, vomiting, disruptions with work, frequent medical visits and concerns about the course of pregnancy and childbirth are some of the many causes of anxiety and depression in pregnant women [1,2]. One of the factors that may also affect the mental health of pregnant women is uncertainties related to catastrophic events, which includes the COVID-19 pandemic [3,4]. According to the review by Salari et al. [5], women during the pandemic are at increased risk of developing depression, anxiety and stress. Social isolation makes it difficult to interact with family and friends [4]; hospital visitation restrictions [6] and fear of the possibility of intrauterine transmission of COVID-19 to the fetus [7] pose challenges to the mental health of mothers-to-be [8]. The WHO (World Health Organization) recognizes 
age, overweight problems and other comorbidities (e.g., hypertension, diabetes) as factors that increase risk of COVID-19 with severe symptomatology for pregnant women [9].

Depressive and anxiety disorders during pregnancy increase the risk of miscarriage [10], preterm labor [11], low birth weight [12] and a low Apgar score (indicates neonatal maladaptation to the intrauterine environment) [13]. On the other hand, high levels of stress in pregnant women may result in the development of emotional, behavioral and cognitive problems in their children [14]. According to a review by Dennis et al. [15], in the first trimester of pregnancy the frequency of anxiety symptoms reported by pregnant women is $18.2 \%$, in the second trimester $19.1 \%$ and in the third trimester $24.6 \%$. Furthermore, anxiety can persist after birth of the baby; it is estimated that nearly $15 \%$ of postpartum women may have suffered from it. In turn, according to a study conducted during the COVID-19 pandemic for women in perinatal and postpartum periods, anxiety rates ranged from 18 to $56 \%$, while simultaneous anxiety and depressive disorders were experienced by 10 to $33 \%$ of women [16]. It has been observed that during the pandemic, there were concerns that COVID-19 could cause fetal structural abnormalities, limit the growth of children or cause preterm births [17]. Similar results were obtained by $\mathrm{Ng}$ et al. [18], who also reported higher rates of anxiety in pregnant women resulting from fear of intrauterine transmission of the SARS-CoV-2 virus and its possible consequences.

The negative impact of stress on the quality of life of pregnant women during the COVID-19 pandemic can be minimized by moderate-intensity physical activity [19]. Physical activity before and/or during pregnancy, pregnancy and the postpartum peri-od, and in the postpartum itself reduces the risk of developing and symptoms of perinatal and postpartum depression [20,21]. According to recommendations of the ACOG (The American College of Obstetricians and Gynecologists), a pregnant woman with a normal course should perform moderate-intensity aerobic exercise for at least $150 \mathrm{~min}$ per week [22]. Exercise has positive effects on the quality of life, the level of anxiety, stress and fatigue in women in the perinatal and postpartum periods $[20,21]$. Additionally, many pregnant women try to find positive aspects of the current situation and develop hobbies at home [23].

The aim of this study was to determine the impact of the COVID-19 pandemic on women's levels of physical activity in the third trimester of pregnancy, their life satisfaction and stress during late pregnancy and early postpartum. In our study, we compared the psychophysical condition of women who gave birth during different periods of the pandemic (December 2019-March 2020, May-September 2020, June-September 2021). To our knowledge, there are currently no publications assessing the psychophysical condition of women who gave birth in Poland during three different periods of the pandemic [24-27].

\section{Materials and Methods}

\subsection{Participants}

The study was conducted among patients of maternity wards hospitals in Cracow, Poland. The project involved 740 women who were on days 1-8 postpartum (vaginal or cesarean section). Due to the COVID-19 pandemic, women were divided into three groups: prepandemic, COVID 1 and COVID 2. Women in the prepandemic group were studied before the COVID-19 pandemic_from December 2019 to March $2020(n=252)$. Seventeen patients refused to participate in the study. Ultimately, 319 questionnaires were distributed. Sixty-five patients returned empty questionnaires and two patients were discharged from the hospital and did not return questionnaires. As a result of restrictions imposed, the project was suspended and resumed in May 2020, in the early stages of the pandemic. Until September 2020, 262 women were examined who were classified as the COVID 1 group. During this period, 379 women were invited to the study, but 22 of them refused to participate due to their lack of time, 93 returned empty questionnaires and 1 patient discharged from the hospital took the questionnaire with her. Additionally, 1 patient was beyond the 8th day of postpartum. The third group of patients was surveyed from June to September 2021 after introduction of population vaccinations against SARS-CoV-2 (COVID 2 group: $n=226)$. In this late stage of the pandemic, 323 patients were enrolled in the 
study. Fifteen of them immediately refused to participate (the reason-lack of time), while 78 women did not complete any questionnaires at all, and 2 patients discharged from the hospital did not return their questionnaires. Moreover, 2 patients were more than 8 days past the postpartum period.

The inclusion criteria for the study were as follows: age over 18; in the 1st to 8 th days of early puerperium; Polish-speaking; and with informed consent given to participate in the study and to data processing. The exclusion criteria were the following: refusal to participate in the study; being under 18 years of age; not Polish-speaking; and being beyond the eighth day of the postpartum period. The study did not establish an upper age limit for the surveyed women. At any time during the survey, patients could resign from further participation without giving any reason.

Participation in the study was voluntary. Informed consent was obtained from all participants. This study was conducted in accordance with the Helsinki Declaration and obtained approval from the Bioethics Committee of Jagiellonian University (Opinion No. 1072.6120.251.2019 of 24 October 2019).

\subsection{Measures}

The research tools used were the original questionnaire (patient's record) in addition to standardized questionnaires assessing physical activity, life satisfaction and stress levels. The authors' questionnaire included questions about basic patient information (e.g., age, marital status, education, place of residence), pregnancy and the course of childbirth (e.g., number of deliveries, types of earlier deliveries, complications during childbirth). Physical activity was assessed using the Pregnancy Physical Activity Questionnaire (PPAQ) [28], Polish version [29]. The PPAQ contains 35 questions divided into the following sections: outside work, travel, entertainment and sports and work. On the basis of obtained responses, it is possible to calculate the average weekly energy expenditure for a given activity. Women were asked to specify the amount of time spent on an activity (depending on the question: $0-6 \mathrm{~h}$ or more per day, $0-3 \mathrm{~h}$ or more per week) [28-30]. The level of satisfaction with life was determined on the basis of the Satisfaction with Life Scale (SWLS), using the Polish version adapted by Juczyński Z. [31]. The SWLS scale consists of 5 statements, which are rated on a scale from 1 ('completely disagree', low life satisfaction) to 7 ('completely agree', high life satisfaction). The sum of points from all statements determines the so-called general index of satisfaction with life. The score range is between 5 and 35 points. The higher the total score obtained in the SWLS, the higher the satisfaction with life. Cronbach's alpha reliability index for the SWLS is 0.81 (Polish version) [31,32]. The SWLS scale is a frequently used scale to assess life satisfaction in perinatal women [33-37]. Stress was assessed on the basis of the Perceived Stress Scale (PSS-10), using the Polish version adapted by Juczyński and Ogińska-Bulik [38]. The PSS-10 contains 10 questions on subjective feelings about problems, personal events and behavior in stressful situations during the past month. Each question is rated on a scale from 0 ('never') to 4 ('very often'), and the final score is between 0 and 40 points. The higher the total score obtained by the patient, the higher the level of perceived stress. Cronbach's alpha reliability index for the PSS-10 is 0.86 (Polish version) [38,39]. The PSS-10 scale can be used to assess the perceived stress in women during the perinatal period $[8,24,25]$.

\subsection{Statistical Analysis}

A priori, the required sample size was calculated. We assumed a Type I error of 0.05 and conservatively set the power at a very high level of 95\%. Additionally, we allowed the possibility of using non-parametric tests by incorporating the Pitman ARE (asymptotic relative efficiency) correction. Under such circumstances, we estimated that 723 persons were sufficient to detect differences of a small effect size (0.15) in the distribution of total physical activity among three groups of roughly equal sizes.

The PS Imago Pro 7 program and R software version 4.0.2 (Development Core Team, Vienna, Austria) were used for statistical analyses. Normality of the obtained data was assessed 
using the Shapiro-Wilk test. The Kruskal-Wallis test followed by the Wilcoxon rank-sum test with Bonferroni correction for pairwise comparisons were applied to check differences among three independent groups and to identify which pairs differed. A chi-square test of independence was performed to evaluate the relationship between two qualitative variables. Correlations between total physical activity and its components were estimated with Spearman rank correlation coefficients. A multivariable linear regression analysis was used to find factors which influenced energy expenditure on total physical activity and its domains. Possible confounders were identified based on the literature. For each subscale and for physical activity in total, the separate models were fitted with different sets of covariates included to check robustness of the findings. Unstandardized $\beta$-coefficients were presented as size effects reflecting the associations. A value of $p<0.05$ was considered significant.

\section{Results}

Detailed characteristics of the study group are presented in Table 1 . In all three groups the median age of participants was 31 years. In all groups, the majority of women were married, lived in large cities and had higher education. There were also higher percentages of vaginal deliveries than caesarean sections, but the differences were not statistically significant. It was observed that in the prepandemic and COVID 2 groups more women were primiparous, while in the COVID 1 group more women were multiparous. Regardless of the examination period, most women planned to become pregnant in their current pregnancies and their deliveries were on time.

Table 1. Characteristics of the studied groups.

\begin{tabular}{|c|c|c|c|c|}
\hline Parameters & $\begin{array}{l}\text { Prepandemic Group } \\
\qquad(N=252)\end{array}$ & $\begin{array}{l}\text { COVID } 1 \text { Group } \\
\quad(N=262)\end{array}$ & $\begin{array}{l}\text { COVID } 2 \text { Group } \\
\quad(N=226)\end{array}$ & $p^{*}$ \\
\hline Age [Me (Q1; Q3)] & $31.0(27.8 ; 33.3)$ & $31.0(28.3 ; 34.0)$ & $31.0(28.0 ; 33.8)$ & 0.110 \\
\hline $\begin{array}{l}\text { Marital status }[n / \%] \\
\text { Single } \\
\text { A partnership } \\
\text { Married }\end{array}$ & $\begin{array}{c}9 / 3.6 \\
41 / 16.3 \\
202 / 80.1\end{array}$ & $\begin{array}{c}9 / 3.4 \\
27 / 10.3 \\
226 / 86.3\end{array}$ & $\begin{array}{c}5 / 2.2 \\
20 / 8.8 \\
201 / 88.9\end{array}$ & 0.079 \\
\hline $\begin{array}{c}\text { Place of residence }[n / \%] \\
\text { Village } \\
\text { City }<100,000 \\
\text { City }>100,000\end{array}$ & $\begin{array}{c}59 / 23.4 \\
25 / 9.9 \\
168 / 66.7\end{array}$ & $\begin{array}{c}72 / 27.5 \\
26 / 9.9 \\
164 / 62.6\end{array}$ & $\begin{array}{c}54 / 23.9 \\
33 / 14.6 \\
139 / 61.5\end{array}$ & 0.330 \\
\hline $\begin{array}{c}\text { Education }[n / \%] \\
\text { Primary/vocational/secondary } \\
\text { University }\end{array}$ & $\begin{array}{c}48 / 19.1 \\
203 / 80.9\end{array}$ & $\begin{array}{c}61 / 23.3 \\
201 / 76.7\end{array}$ & $\begin{array}{c}42 / 18.6 \\
184 / 81.4\end{array}$ & 0.359 \\
\hline $\begin{array}{c}\text { Type of delivery }[n / \%] \\
\text { Vaginal delivery } \\
\text { Cesarean section }\end{array}$ & $\begin{array}{c}149 / 63.7 \\
85 / 36.3\end{array}$ & $\begin{array}{l}152 / 58 \\
110 / 42\end{array}$ & $\begin{array}{l}122 / 54.0 \\
104 / 46.0\end{array}$ & 0.105 \\
\hline $\begin{array}{c}\text { Number of deliveries }[n / \%] \\
\text { Primiparous } \\
\text { Multiparous }\end{array}$ & $\begin{array}{l}137 / 54.4 \\
115 / 45.6\end{array}$ & $\begin{array}{l}111 / 42.4 \\
151 / 57.6\end{array}$ & $\begin{array}{l}115 / 50.9 \\
111 / 49.1\end{array}$ & 0.020 \\
\hline $\begin{array}{c}\text { Number of pregnancies } \\
{[\mathrm{Me}(\mathrm{Q} 1 ; \mathrm{Q} 3)]}\end{array}$ & $1(1 ; 2)^{a, \#}$ & $2(1 ; 3)^{a, \#}$ & $2(1 ; 2)$ & 0.002 \\
\hline $\begin{array}{c}\text { Planning the current pregnancy } \\
{[n / \%]} \\
\text { Yes }\end{array}$ & $192 / 76.2$ & $218 / 83.2$ & $185 / 81.9$ & 0.108 \\
\hline $\begin{array}{c}\text { Complications in pregnancy } \\
{[n / \%]} \\
\text { Yes }\end{array}$ & $44 / 19$ & $35 / 13.4$ & $43 / 19$ & 0.152 \\
\hline
\end{tabular}


Table 1. Cont.

\begin{tabular}{ccccc}
\hline Parameters & $\begin{array}{c}\text { Prepandemic Group } \\
(\mathbf{N}=\mathbf{2 5 2})\end{array}$ & $\begin{array}{c}\text { COVID 1 Group } \\
(\mathbf{N}=\mathbf{2 6 2})\end{array}$ & $\begin{array}{c}\text { COVID 2 Group } \\
(\boldsymbol{N}=\mathbf{2 2 6})\end{array}$ & $\boldsymbol{p}^{*}$ \\
\hline $\begin{array}{c}\text { Delivery at term }[n / \%] \\
\text { Yes }\end{array}$ & $140 / 59.8$ & $162 / 61.8$ & $126 / 55.8$ & 0.386 \\
\hline
\end{tabular}

Me-median; Q1-lower quartile; Q3-higher quartile; prepandemic group-participants tested before the pandemic (December 2019 to March 2020); COVID 1 group-participants tested in the early stages of the pandemic (May to September 2020); COVID 2 group-participants tested in the late stages of the pandemic (June to September 2021); ${ }^{\#}$ the same letter denotes significant difference between designated groups: a vs. COVID 1. * based on Kruskal-Wallis test followed by pairwise comparisons using Wilcoxon rank-sum test with Bonferroni correction or chi-square test of independence.

\subsection{Physical Activity}

During hospital stays patients characterized physical activities undertaken in their third trimesters of pregnancy (PPAQ questionnaire). The study showed that the energy spent by women in the third trimester of pregnancy on total physical activity was significantly lower in postpartum women from the COVID 2 group compared to those in the prepandemic group (Me: 146.5, Q1-Q3: 95.1-202.6 MET vs. Me: 170.7, Q1-Q3: 114.1-234.6 MET). Similar differences were not found among participants giving birth in the early part of the pandemic and participants who delivered before or in the late stage of the pandemic. In contrast, women who gave birth between May and September 2020 spent less energy on movement-related activities compared to women from the prepandemic (Me: 8.8, Q1-Q3: 3.4-18.8 MET vs. Me: 14.0, Q1-Q3: 6.7-26.1 MET) and COVID 2 groups (Me: 8.8, Q1-Q3: 3.4-18.8 MET vs. Me: 12.6, Q1-Q3: 5.3-22.6 MET). However, as the pandemic continued, women stopped limiting their activities related to movement. Both prepandemic and late-stage participants spent similar amounts of energy on this type of activity (Me: 14.0, Q1-Q3: 6.7-26.1 MET for prepandemic group vs. Me: 12.6, Q1-Q3: 5.3-22.6 MET for the COVID 2 group). Nevertheless, in the late stage of the pandemic, women spent less energy on domestic activities (Me: 71.1, Q1-Q3: 34.7-132.3 MET) than women giving birth before (Me: 93.5, Q1-Q3: 57.8-141.5 MET) or in the early time of the pandemic (Me: 95.9, Q1-Q3: 46.8-154.0 MET). The detailed characteristics of the obtained results are presented in Table 2.

Table 2. The Level of Physical Activity in the Studied Women.

\begin{tabular}{|c|c|c|c|c|}
\hline & Prepandemic Group & COVID 1 Group & COVID 2 Group & \\
\hline $\begin{array}{l}\text { Physical Activity } \\
\text { [MET-h/Week] }\end{array}$ & $\begin{array}{c}\left(N=220^{\&}\right) \\
M e(Q 1 ; Q 3)\end{array}$ & $\begin{array}{c}\left(N=244^{\&}\right) \\
M e(Q 1 ; Q 3)\end{array}$ & $\begin{array}{c}\left(N=223^{\&}\right) \\
M e(Q 1 ; Q 3)\end{array}$ & $p^{*}$ \\
\hline Total physical activity & $170.7(114.1 ; 234.6)^{b, \#}$ & $150.8(103.0 ; 229.5)$ & $146.5(95.1 ; 202.6)^{b, \#}$ & 0.007 \\
\hline $\begin{array}{l}\text { Sports activity and } \\
\text { physical exercise }\end{array}$ & $3.2(0.9 ; 11.0)$ & $4.5(1.6 ; 12.1)$ & $3.9(1.6 ; 10.8)$ & 0.206 \\
\hline Passive rest & $20.4(12.8 ; 41.0)$ & $17.8(8.9 ; 35.7)$ & $20.0(8.9 ; 34.5)$ & 0.106 \\
\hline Movement & $14.0(6.7 ; 26.1)^{a, \#}$ & $8.8(3.4 ; 18.8)^{a, c, \#}$ & $12.6(5.3 ; 22.6)^{c, \#}$ & $<0.001$ \\
\hline Household activities & $93.5(57.8 ; 141.5) b, \#$ & $95.9(46.8 ; 154.0)^{c, \#}$ & $71.1(34.7 ; 132.3))^{b, c, \#}$ & 0.001 \\
\hline Occupational activity & $57.8(23.2 ; 76.9)$ & $52.9(22.4 ; 78.2)$ & $67.1(32.5 ; 74.3)$ & 0.979 \\
\hline
\end{tabular}

Me-median; Q1-lower quartile; Q3-higher quartile; prepandemic group-participants tested before the pandemic (December 2019 to March 2020); COVID 1 group-participants tested in the early stages of the pandemic (May to September 2020); COVID 2 group - participants tested in the late stages of the pandemic (June to September 2021); ${ }^{\#}$ the same letter denotes significant difference between designated groups: ${ }^{\text {a }}$-prepandemic vs. COVID 1, b-prepandemic vs. COVID 2, c-COVID 1 vs. COVID 2; MET-h/week-metabolic equivalent of task (average weekly energy expenditure: MET-hour/week); * based on Kruskal-Wallis test followed by pairwise comparisons using Wilcoxon rank-sum test with Bonferroni correction; \& for work-related activities: prepandemic group $N=67$, COVID 1 group $N=58$, COVID 2 group $N=63$. 
Most components of physical activity significantly correlated with total physical activity, with the strongest effect observed for household activities $(\mathrm{r}=0.786, p<0.001)$, occupational activities $(\mathrm{r}=0.584, p<0.001)$ and movement $(\mathrm{r}=0.497, p<0.001)$. However, the correlations between particular domains were rather weak and estimated at a level below 0.278 on absolute value. Most of the pairwise comparisons showed positive associations except household activities, which correlated negatively with passive rest $(\mathrm{r}=-0.261$, $p<0.001)$. The correlation results are presented in Table 3 .

Table 3. Spearman's Rank Correlations between Total Physical Activity [MET-h/Weeks] and its Components.

\begin{tabular}{ccccccc}
\hline Lp & Physical Activity & $\mathbf{1}$ & $\mathbf{2}$ & $\mathbf{3}$ & $\mathbf{4}$ & $\mathbf{6}$ \\
\hline 1 & Total physical activity & 1.000 & & & & \\
\hline 2 & $\begin{array}{c}\text { Sports activity and } \\
\text { physical exercise }\end{array}$ & $0.244^{* * *}$ & 1.000 & & & \\
\hline 3 & Passive rest & $0.118^{* *}$ & $0.081^{*}$ & 1.000 & & \\
\hline 4 & Movement & $0.497^{* * *}$ & $0.210^{* * *}$ & $0.096^{*}$ & 1.000 & 1.000 \\
\hline 5 & Household activities & $0.786^{* * *}$ & $0.107^{* *}$ & $-0.261^{* * *}$ & $0.278^{* * *}$ & $0.207^{* *}$ \\
\hline 6 & Occupational activity & $0.584^{* * *}$ & 0.040 & $0.230^{* *}$ & -0.005 & 1.000 \\
\hline
\end{tabular}

*** $p<0.001,{ }^{* *} p<0.01,{ }^{*} p<0.05$

\subsection{Levels of Life Satisfaction and Stress in Women}

Life satisfaction was assessed using the SWLS scale categorized into low (values 1-4 sten), average (5-6 sten scores) and high (7-10 sten) [31]. Regardless of the period of the study, most of the patients felt high satisfaction with their lives (prepandemic: $66.3 \%$, COVID 1: $70.0 \%$ and COVID 2: $67.4 \%$ of women in each group). Nevertheless, no statistically significant differences in the degree of life satisfaction were observed among the women studied. The level of perceived stress was also characterized in the patients. As a result of the fact that the PSS-10 stress scale is a sten scale, the levels of stress were also divided into low (1-4 sten scores), moderate (5-6 sten values) and high (7-10 sten scores) [38]. The distributions of stress levels in all studied groups were similar. The obtained results of descriptive and test statistics are presented in Table 4.

Table 4. Levels of Life Satisfaction and Perceived Stress of Women.

\begin{tabular}{|c|c|c|c|c|}
\hline \multirow{2}{*}{ Parameters } & Prepandemic Group & COVID 1 Group & COVID 2 Group & $p^{*}$ \\
\hline & $(N=252)$ & $(N=262)$ & $(N=226)$ & \\
\hline SWLS [Me (Q1; Q3)] & $26.0(23.0 ; 29.0)$ & $26.0(23.0 ; 29.0)$ & $25.0(22.0 ; 28.0)$ & 0.625 \\
\hline $\begin{array}{c}\text { SWLS }[n / \%] \\
\text { Low } \\
\text { Moderate } \\
\text { High }\end{array}$ & $\begin{array}{c}16 / 6.6 \\
66 / 27.2 \\
161 / 66.3\end{array}$ & $\begin{array}{c}8 / 3.3 \\
65 / 26.7 \\
170 / 70.0\end{array}$ & $\begin{array}{c}12 / 5.4 \\
60 / 27.1 \\
149 / 67.4\end{array}$ & 0.571 \\
\hline Stress [Me (Q1; Q3)] & $18.0(13.0 ; 22.0)$ & $17.0(13.0 ; 22.0)$ & $17.0(13.0 ; 22.0)$ & 0.974 \\
\hline $\begin{array}{c}\text { Stress }[n / \%] \\
\text { Low } \\
\text { Moderate } \\
\text { High }\end{array}$ & $\begin{array}{l}68 / 27.9 \\
81 / 33.2 \\
95 / 38.9\end{array}$ & $\begin{array}{l}70 / 29.3 \\
85 / 35.6 \\
84 / 35.1\end{array}$ & $\begin{array}{l}58 / 26.6 \\
78 / 35.8 \\
82 / 37.6\end{array}$ & 0.902 \\
\hline
\end{tabular}

Me-median; Q1-lower quartile; Q3-higher quartile; prepandemic group-participants tested before the pandemic (December 2019 to March 2020); COVID 1 group-participants tested in the early stages of the pandemic (May to September 2020); COVID 2 group-participants tested in the late stages of the pandemic (June to September 2021); * based on Kruskal-Wallis test or chi-square test of independence.

However, both in participants giving birth before, as well as in the early and late periods of the COVID-19 pandemic, it was observed that with increasing life satisfaction, 
the level of perceived stress decreased. Nevertheless, in the groups studied during the pandemic the correlation coefficients were weak (COVID 1 group: $\mathrm{r}=-0.385, p<0.001$; COVID 2 group: $\mathrm{r}=-0.331, p<0.001)$. A stronger correlation between life satisfaction and perceived stress was demonstrated among women examined before the pandemic $(\mathrm{r}=-0.420, p<0.001)$. Results of the conducted correlations are presented in Table 5 .

Table 5. Spearman's Rank Correlations between the Levels of Life Satisfaction and Perceived Stress.

\begin{tabular}{ccccccc}
\hline Group & Prepandemic Group & \multicolumn{2}{c}{ COVID 1 Group } & \multicolumn{2}{c}{ COVID 2 Group } \\
\hline Parameters & $p$ & $\begin{array}{c}\text { Spearman's } \\
\text { Rank }\end{array}$ & $p$ & $\begin{array}{c}\text { Spearman's } \\
\text { Rank }\end{array}$ & $p$ & $\begin{array}{c}\text { Spearman's } \\
\text { Rank }\end{array}$ \\
\hline $\begin{array}{c}\text { SWLS vs. } \\
\text { PSS-10 }\end{array}$ & $<0.001$ & -0.420 & $<0.001$ & -0.385 & $<0.001$ & -0.331 \\
\hline
\end{tabular}

Statistical significance for $p<0.05$; Spearman's rank-Spearman's rank correlation coefficient; prepandemic group-participants tested before the pandemic (December 2019 to March 2020); COVID 1 group-participants tested in the early stages of the pandemic (May to September 2020); COVID 2 group-participants tested in the late stages of the pandemic (June to September 2021).

\subsection{Levels of Physical Activity and Life Satisfaction}

Correlations were made between the parameters of physical activity and life satisfaction. A negative correlation between the degree of life satisfaction and the amount of energy devoted to passive rest was observed among patients from the prepademic group $(r=-0.153, p=0.024)$. No similar correlations were found between the other variables among all groups (Table 6).

Table 6. Spearman's Rank Correlations-Physical Activity and Life Satisfaction.

\begin{tabular}{|c|c|c|c|c|c|c|}
\hline \multicolumn{7}{|c|}{ Satisfaction of Life } \\
\hline \multirow{2}{*}{$\begin{array}{c}\text { Group } \\
\text { Parameters }\end{array}$} & \multicolumn{2}{|c|}{ Prepandemic Group } & \multicolumn{2}{|c|}{ COVID 1 Group } & \multicolumn{2}{|c|}{ COVID 2 Group } \\
\hline & $p$ & $\begin{array}{c}\text { Spearman's } \\
\text { Rank }\end{array}$ & $p$ & $\begin{array}{c}\text { Spearman's } \\
\text { Rank }\end{array}$ & $p$ & $\begin{array}{c}\text { Spearman's } \\
\text { Rank }\end{array}$ \\
\hline Total physical activity & 0.480 & 0.048 & 0.601 & -0.035 & 0.291 & -0.072 \\
\hline $\begin{array}{l}\text { Sports activity and } \\
\text { physical exercise }\end{array}$ & 0.177 & 0.092 & 0.174 & 0.091 & 0.333 & 0.066 \\
\hline Passive rest & 0.024 & -0.153 & 0.114 & -0.105 & 0.400 & -0.057 \\
\hline Movement & 0.747 & -0.022 & 0.663 & -0.029 & 0.340 & -0.065 \\
\hline Household activities & 0.247 & 0.079 & 0.493 & -0.046 & 0.252 & -0.078 \\
\hline Occupational activity & 0.261 & 0.076 & 0.129 & 0.052 & 0.590 & 0.037 \\
\hline
\end{tabular}

Statistical significance for $p<0.05$; Spearman's rank-Spearman's rank correlation coefficient; prepandemic group-participants tested before the pandemic (December 2019 to March 2020); COVID 1 group-participants tested in the early stages of the pandemic (May to September 2020); COVID 2 group-participants tested in the late stages of the pandemic (June to September 2021).

\subsection{Physical Activity and the Level of Perceived Stress}

The analysis of individual components of physical activity in relation to the level of perceived stress by women from all groups was also performed. It should be noted that in women giving birth before the pandemic, higher levels of stress correlated with lower energy expenditure on sports activities $(r=-0.134, p=0.048)$. On the other hand, among participants giving birth at the initial stage of the pandemic, a positive correlation was observed between the level of stress and the amount of energy spent on domestic activities $(r=0.149, p=0.026)$. No similar relationships were found between other types of physical activity and the level of stress-Table 7. 
Table 7. Spearman's Rank Correlations-Physical Activity and Stress.

\begin{tabular}{|c|c|c|c|c|c|c|}
\hline \multicolumn{7}{|c|}{ Level of Perceived Stress } \\
\hline \multirow{2}{*}{$\begin{array}{c}\text { Group } \\
\text { Parameters }\end{array}$} & \multicolumn{2}{|c|}{ Prepandemic Group } & \multicolumn{2}{|c|}{ COVID 1 Group } & \multicolumn{2}{|c|}{ COVID 2 Group } \\
\hline & $p$ & $\begin{array}{c}\text { Spearman's } \\
\text { Rank }\end{array}$ & $p$ & $\begin{array}{c}\text { Spearman's } \\
\text { Rank }\end{array}$ & $p$ & $\begin{array}{c}\text { Spearman's } \\
\text { Rank }\end{array}$ \\
\hline Total physical activity & 0.469 & 0.049 & 0.060 & 0.126 & 0.943 & -0.005 \\
\hline $\begin{array}{l}\text { Sports activity and } \\
\text { physical exercise }\end{array}$ & 0.048 & -0.134 & 0.059 & -0.127 & 0.317 & -0.068 \\
\hline Passive rest & 0.322 & 0.067 & 0.660 & -0.030 & 0.996 & 0.000 \\
\hline Movement & 0.580 & 0.038 & 0.287 & 0.072 & 0.837 & -0.014 \\
\hline Household activities & 0.966 & 0.003 & 0.026 & 0.149 & 0.371 & 0.061 \\
\hline Occupational activity & 0.823 & 0.015 & 0.325 & -0.066 & 0.123 & -0.105 \\
\hline
\end{tabular}

\subsection{Level of Physical Activity-Multivariable Linear Regression Analysis}

Multivariable linear regression analysis was performed to check associations between total physical activity and its subdomains during the period of pandemic, SWLS, stress and other factors after controlling for other confounders. The analysis revealed that independently of the remaining covariates, women from the COVID 1 and COVID 2 groups had significantly lower levels of physical activity in total, as well as in household activities, compared with the prepandemic group $(\beta=-17.7,95 \% \mathrm{CI}:-35.2$ to -0.3 and $\beta=-14.4$, 95\% CI: -27.1 to -1.8 for COVID 1 compared with the prepandemic group; $\beta=-26.1$, $95 \%$ CI: -43.7 to -8.5 and $\beta=-24.1,95 \%$ CI: -36.8 to -11.4 for COVID 2 compared with the prepandemic group, respectively, in fully adjusted models). Moreover, a decreasing trend across considered groups was observed with the strongest decline for women who gave birth during the late stage of the pandemic (COVID 2 group). Additionally, a decrease in movement for women during the first period of the pandemic (COVID 1 group) was detected; however, later in the pandemic movement assessment results stabilized with no differences between the COVID 2 and prepandemic groups found. One unit increase in score of overall satisfaction from life was associated with lower energy expenditure on passive rest ( $\beta=-0.6,95 \% \mathrm{CI}:-0.9$ to -0.2 in Model 3). The results for stress did not show any stable and robust relationship with any domain of physical activity. However, in model 1 it was noted that as perceived stress increased by one unit, participants increased energy expenditure on total physical activity ( $\beta=1.3,95 \%$ CI: 0.1 to 2.5 ) and household activities ( $\beta=1.1,95 \%$ CI: 0.2 to 2.1 ). However, unmarried women devoted much more energy to total activity, as well as to passive rest, movement, household activities and activities related to work ( $\beta=42.4,95 \%$ CI: 20.3 to $64.6 ; \beta=4.6,95 \%$ CI: 0.0 to $9.2 ; \beta=7.7,95 \%$ CI: 2.9 to $12.6 ; \beta=14.9,95 \%$ CI: 0.3 to 29.6 ; and $\beta=23.4,95 \%$ CI: 5.9 to 40.9 , respectively). On the other hand, women who lived in villages and in cities (up to 100,000 inhabitants) spent significantly less energy on passive rest $(\beta=-5.8,95 \%$ CI: -9.4 to -2.3 and $\beta=-4.9$, $95 \%$ CI: -9.8 to -0.1 , respectively) and more on home activities ( $\beta=14.3,95 \%$ CI: 2.0 to 26.6 and $\beta=17.8,95 \%$ CI: 0.9 to 34.7). In addition, participants living in villages had lower energy expenditures on sports activities compared to women living in large cities ( $\beta=-2.9$, $95 \%$ CI: $-4.8 ;-0.9)$. It was also observed that regardless of other covariates, multiparous women had significantly higher levels of total physical activity ( $\beta=53.7,95 \%$ CI: 37.8 to 69.6) and household activities ( $\beta=74.7,95 \%$ CI: 63.2 to 86.2 ) compared to primiparaous women. However, multiparous women spent less energy on sports activities $(-2.2,95 \% \mathrm{CI}$ : -4.0 to -0.4$)$ and passive rest $(-14.7,95 \% \mathrm{CI}:-18.0$ to -11.3$)$. The exact results of the regression analysis are shown in Table 8. 
Table 8. Regression Analysis.

\begin{tabular}{|c|c|c|c|c|c|c|c|}
\hline Variable & Compared Categories & $\begin{array}{c}\text { Total Physical Activity } \\
\text { [MET-h/Week] }\end{array}$ & $\begin{array}{l}\text { Sports Activity and } \\
\text { Physical Exercise } \\
\text { [MET-h/week] }\end{array}$ & $\begin{array}{l}\text { Passive Rest } \\
\text { [MET-h/Week] }\end{array}$ & $\begin{array}{c}\text { Movement } \\
\text { [MET-h/Week] }\end{array}$ & $\begin{array}{l}\text { Household Activities } \\
\text { [MET-h/Week] }\end{array}$ & $\begin{array}{l}\text { Occupational Activity } \\
\text { [MET-h/Week] }\end{array}$ \\
\hline & & $\beta(95 \% \mathrm{CI})$ & $\beta(95 \% \mathrm{CI})$ & $\beta(95 \% \mathrm{CI})$ & $\beta(95 \% \mathrm{CI})$ & $\beta(95 \% \mathrm{CI})$ & $\beta(95 \% \mathrm{CI})$ \\
\hline \multirow{8}{*}{ Group } & \multicolumn{7}{|l|}{ COVID 1 vs. Prepandemic } \\
\hline & Model $1{ }^{\#}$ & $-19.1(-36.8 ;-1.4)^{* * *}$ & $0.7(-1.3 ; 2.6)$ & $-3.2(-7.1 ; 0.7)$ & $-5.5(-9.3 ;-1.7) *$ & $-7.1(-21.0 ; 6.8)$ & $-1.4(-19.4 ; 16.6)$ \\
\hline & Model 2 \#\# & $-21.0(-38.1 ;-3.9)^{* * *}$ & $1.1(-0.8 ; 3.0)$ & $-0.9(-4.5 ; 2.8)$ & $-5.2(-9.0 ;-1.4) *$ & $-14.6(-26.9 ;-2.3)^{* * *}$ & $4.0(-14.0 ; 21.9)$ \\
\hline & Model 3 \#\#\# & $-17.7(-35.2 ;-0.3)^{* * *}$ & $1.1(-0.9 ; 3.1)$ & $0.1(-3.5 ; 3.7)$ & $-4.3(-8.2 ;-0.5)^{* * *}$ & $-14.4(-27.1 ;-1.8)^{* * *}$ & $2.4(-16.4 ; 21.2)$ \\
\hline & \multicolumn{7}{|l|}{ COVID 2 vs. Prepandemic } \\
\hline & Model 1 ${ }^{\#}$ & $-32.9(-50.7 ;-15.1)^{* * *}$ & $0.6(-1.4 ; 2.5)$ & $-4.1(-8.1 ;-0.2)^{* * *}$ & $-2.6(-6.4 ; 1.2)$ & $-24.3(-38.3 ;-10.3)^{* * *}$ & $-5.4(-22.8 ; 12.1)$ \\
\hline & Model 2 & $-29.4(-46.6 ;-12.1)^{* * *}$ & $0.7(-1.2 ; 2.7)$ & $-3.0(-6.6 ; 0.7)$ & $-2.1(-5.9 ; 1.7)$ & $-24.6(-37.1 ;-12.2)^{* * *}$ & $-0.8(-18.3 ; 16.6)$ \\
\hline & Model 3 \#\#\# & $-26.1(-43.7 ;-8.5)^{*}$ & $0.6(-1.4 ; 2.6)$ & $-2.0(-5.7 ; 1.7)$ & $-1.1(-4.9 ; 2.8)$ & $-24.1(-36.8 ;-11.4)^{* * *}$ & $-0.9(-19.2 ; 17.4)$ \\
\hline \multirow{4}{*}{ SWLS } & \multicolumn{7}{|l|}{ per 1 unit } \\
\hline & Model 1 $\#$ & $0.5(-1.2 ; 2.2)$ & $0.1(0.0 ; 0.3)$ & $-0.6(-1.0 ;-0.3)^{* * *}$ & $0.1(-0.2 ; 0.5)$ & $0.4(-0.9 ; 1.7)$ & $-0.1(-1.9 ; 1.8)$ \\
\hline & Model 2 \#\# & $1.0(-0.7 ; 2.6)$ & $0.1(0.0 ; 0.3)$ & $-0.6(-0.9 ;-0.2) *$ & $0.2(-0.2 ; 0.5)$ & $0.5(-0.7 ; 1.7)$ & $0.0(-1.8 ; 1.9)$ \\
\hline & Model $3{ }^{\# \# \#}$ & $1.1(-0.6 ; 2.8)$ & $0.1(0.0 ; 0.3)$ & $-0.6(-0.9 ;-0.2)^{*}$ & $0.3(-0.1 ; 0.6)$ & $0.5-0.7 ; 1.7)$ & $0.5(-1.5 ; 2.4)$ \\
\hline \multirow{4}{*}{ Stress } & \multicolumn{7}{|l|}{ per 1 unit } \\
\hline & Model 1 $\#$ & $1.3(0.1 ; 2.5)^{* * *}$ & $-0.1(-0.2 ; 0.1)$ & $0.0(-0.3 ; 0.3)$ & $0.2(0.0 ; 0.5)$ & $1.1(0.2 ; 2.1)^{* * *}$ & $0.1(-1.1 ; 1.4)$ \\
\hline & Model $2 \#$ & $1.1(-0.1 ; 2.3)$ & $0.0(-0.2 ; 0.1)$ & $0.2(-0.1 ; 0.4)$ & $0.2(0.0 ; 0.5)$ & $0.6(-0.2 ; 1.4)$ & $0.2(-1.0 ; 1.4)$ \\
\hline & Model 3 \#\#\# & $1.1(0.0 ; 2.3)$ & $0.0(-0.2 ; 0.1)$ & $0.2(-0.1 ; 0.4)$ & $0.3(0.0 ; 0.5)^{* * *}$ & $0.5(-0.3 ; 1.4)$ & $0.5(-0.8 ; 1.8)$ \\
\hline \multirow{4}{*}{ Marital status } & \multicolumn{7}{|l|}{ Unmarried vs. Married } \\
\hline & Model 1 ${ }^{\#}$ & - & - & - & - & - & - \\
\hline & Model 2 \#\# & $49.3(29.1 ; 69.6)^{* * *}$ & $0.4(-1.9 ; 2.7)$ & $7.8(3.5 ; 12.1)^{* * *}$ & $7.4(2.9 ; 11.9)^{*}$ & $14.9(0.3 ; 29.6)^{* * *}$ & $23.4(5.9 ; 40.9)^{*}$ \\
\hline & Model $33^{\# \#}$ & $42.4(20.3 ; 64.6)^{* * *}$ & $0.8(-1.8 ; 3.3)$ & $4.6(0.0 ; 9.2) *$ & $7.7(2.9 ; 12.6) *$ & $11.7(-4.3 ; 27.7)$ & $15.6(-4.1 ; 35.3)$ \\
\hline
\end{tabular}


Table 8. Cont.

\begin{tabular}{|c|c|c|c|c|c|c|c|}
\hline Variable & Compared Categories & $\begin{array}{l}\text { Total Physical Activity } \\
\text { [MET-h/Week] }\end{array}$ & $\begin{array}{l}\text { Sports Activity and } \\
\text { Physical Exercise } \\
\text { [MET-h/week] }\end{array}$ & $\begin{array}{l}\text { Passive Rest } \\
\text { [MET-h/Week] }\end{array}$ & $\begin{array}{c}\text { Movement } \\
\text { [MET-h/Week] }\end{array}$ & $\begin{array}{l}\text { Household Activities } \\
\text { [MET-h/Week] }\end{array}$ & $\begin{array}{l}\text { Occupational Activity } \\
\text { [MET-h/Week] }\end{array}$ \\
\hline \multirow{6}{*}{ Place of residence } & \multicolumn{7}{|c|}{ City $<100,000$ vs. City $>100,000$} \\
\hline & Model 2 \#\# & $22.3(-0.5 ; 45.1)$ & $-2.1(-4.7 ; 0.5)$ & $-3.9(-8.8 ; 1.0)$ & $2.7(-2.3 ; 7.8)$ & $19.9(3.5 ; 36.3)^{* * *}$ & $5.4(-15.9 ; 26.6)$ \\
\hline & Model 3 \#\#\# & $16.7(-6.7 ; 40.1)$ & $-2.2(-4.9 ; 0.4)$ & $-4.9(-9.8 ;-0.1)^{* * *}$ & $1.7(-3.4 ; 6.9)$ & $17.8(0.9 ; 34.7)^{* * *}$ & $1.7(-21.0 ; 24.3)$ \\
\hline & \multicolumn{7}{|l|}{ Village vs. City $>100,000$} \\
\hline & Model $2{ }^{\#}$ & $6.3(-10.1 ; 22.6)$ & $-2.9(-4.8 ;-1.1)^{*}$ & $-5.4(-8.9 ;-1.9)^{*}$ & $0.3(-3.3 ; 3.9)$ & $18.2(6.4 ; 30.0)^{*}$ & $-11.6(-29.3 ; 6.2)$ \\
\hline & Model 3 \#\#\# & $1.3(-15.7 ; 18.4)$ & $-2.9(-4.8 ;-0.9) *$ & $-5.8(-9.4 ;-2.3)^{*}$ & $-1.2(-5.0 ; 2.5)$ & $14.3(2.0 ; 26.6)^{* * *}$ & $-11.4(-29.8 ; 7.1)$ \\
\hline \multirow{4}{*}{ Number of deliveries } & \multicolumn{7}{|c|}{ Multiparous vs. Primiparous } \\
\hline & Model $1^{\#}$ & - & - & - & - & - & - \\
\hline & Model 2 \#\# & $48.2(33.9 ; 62.5)^{* * *}$ & $-2.6(-4.2 ;-1.0)^{*}$ & $-14.4(-17.4 ;-11.3)^{* * *}$ & $1.3(-1.9 ; 4.4)$ & $69.5(59.2 ; 79.8)^{* * *}$ & $-2.4(-17.1 ; 12.3)$ \\
\hline & Model $3^{\# \# \#}$ & $53.7(37.8 ; 69.6)^{* * *}$ & $-2.2(-4.0 ;-0.4)^{* * *}$ & $-14.7(-18.0 ;-11.3)^{* * *}$ & $2.7(-0.8 ; 6.2)$ & $74.7(63.2 ; 86.2)^{* * *}$ & $-2.6(-20.1 ; 14.9)$ \\
\hline
\end{tabular}

${ }^{* * *} p<0.001, * p<0.05 ;{ }^{*}$ Model 1 includes: group (COVID 1/COVID 2/prepandemic (ref.)), SWLS (score), stress (score); \#\# Model 2 includes: group (COVID 1/COVID 2/prepandemic (ref.)), SWLS (score), stress (score), marital status (unmarried/married (ref.)), place of residence (village/city $<100,000 /$ city $>100,000$ (ref.)), number of deliveries (multiparous/primiparous (ref.)), education (primary or vocational or secondary/university (ref.)), planning the current pregnancy (yes/no (ref.)), complications in pregnancy(no/yes (ref.)): \#\#\# Model 3 includes: group (COVID 1/COVID 2/prepandemic (ref.)), SWLS (score), stress (score), marital status (unmarried/married (ref)), place of residence (village/city < ( (yes/no (ref.)), complications in pregnancy(no/yes (ref.)), age (years), delivery at term (yes/no (ref.)), type of delivery (cesarean section/vaginal delivery (ref.)). 


\section{Discussion}

The aim of this study was to determine the impact of the COVID-19 pandemic on the levels of physical activity during the third trimester of pregnancy, life satisfaction and perceived stress in women in late pregnancy and in early postpartum during the period from December 2019 to September 2021. In our study, we observed that both women who gave birth in the initial and late stages of the pandemic decreased their level of energy spent on total physical activity compared to women giving birth before the pandemic. We did not notice similar differences in levels of perceived stress and life satisfaction.

In recent years, physical activity during pregnancy has been recommended as a factor supporting the physiological course of pregnancy and childbirth [40]. Due to the many benefits of regular activity during the perinatal period, pregnant women often modify their previous behavior and adapt to principles of a healthy lifestyle [41]. Nevertheless, pain, fear of harming the baby and of miscarriage or premature birth, in addition to fear of suffering an injury and lacking sufficient knowledge, are some of the most commonly reported reasons for not being active during pregnancy [42,43]. Changes in the level of physical activity may also be caused by the development of anxiety and depressive disorders [44], which may worsen as a result of the current pandemic state [45]. After the announcement of the pandemic and introduction of restrictions, many pregnant or postpartum women reduced their previous physical activity [46].

In our study, we showed that women who gave birth in any period of the pandemic spent less energy on total physical activity in the third trimester of pregnancy (prepandemic Me: 170.7, Q1-Q3: 114.1-234.6 MET; COVID 1 group Me: 150.8, Q1-Q3: 103.0-229.5 MET; and COVID 2 group Me: 146.5, Q1-Q3: 95.1-202.6 MET). For comparison, in a study conducted in 2017 which also considered Polish women in the third trimester of pregnancy, the median energy expenditure for total physical activity was 196.9 MET (Q1-Q3: 137.1-268.9 MET) [47]. In turn, Krzepota el at. [30] observed that when examining the same pregnant women in a one-week time interval, the energy expenditure for total activity could decrease from 214.64 MET to 192.35 MET (Q1-Q3: 172.08-274.38 and 149.24-248.93 MET, respectively). Other studies conducted among women in their second and third trimesters showed that levels of total physical activity regardless of the period of pregnancy were similar and amounted to 166.8 MET (Q1-Q3: 129.1-220.7 MET) and 168.8 MET (Q1-Q3: 130.4-227.2 MET), respectively [48]. Comparing our results with the results obtained by other researchers, it can be observed that during the pandemic, women had lower overall physical activity. Based on linear regression analysis of many variables, we showed that regardless of the remaining covariates, women giving birth during the early and late stages of the pandemic had significantly lower levels of overall physical activity compared to women giving birth before the pandemic. Moreover, this observed decrease was stronger for women in the COVID 2 group (late stage of pandemic).

We furthermore noted that in each study group, out of all types of activity, participants spent the most energy on household activities. Similar results were also obtained in other studies [30,47-50]. Based on our results of the linear regression analysis, it can be seen that regardless of coexisting factors, pregnant women significantly reduced activities related to movement during the early stage of the pandemic. Similar relationships were not shown in the late period of the pandemic. This difference could be a result of current restrictions, the state of knowledge about virus transmission and the course of infection in pregnant women. On the other hand, there were no significant changes in the levels of energy devoted to passive rest among the surveyed women. Only women from the COVID 2 group, irrespective of life satisfaction and stress, decreased their expenditure on passive activity compared to the prepandemic group. However, no similar relationships were found in the remaining regression models ( 2 and 3 ) as well as in the group of women who gave birth in the early stage of the pandemic. Research by Meaney et al. [51] indicated that women most often try to reduce stress through contact with other people (e.g., talking to their husband/partner, family, friends) and through physical exercise (e.g., walking, yoga, unspecified exercises). Biviá-Roig et al. [52] observed a decrease in overall physical 
activity in pregnant women, which was associated with an increase in time spent in sitting positions (it doubled during the pandemic). In turn, Lebel et al. [53] noted that pregnant women in the early stage of the pandemic were characterized by good physical activity levels. In addition, physical activity reduced psychological symptoms.

A pandemic can have both positive and negative effects on lifestyle. In the study by Hori et al. [54] there were no significant changes in physical activity levels resulting from lifestyle changes during the COVID-19 pandemic for both primaparous and multiparous women. There were moreover no differences in physical activity levels between women who said the pandemic had affected their current activity and those who reported that the pandemic had not affected them. In contrast, our study showed that multiparous women spent more energy on total physical activity and household activities, and significantly less on sports and passive rest compared to primiparous women. Kumari et al. [55] showed that the pandemic changed the daily routines of women during perinatal and postnatal periods, e.g., women reported that they were unable to maintain regular physical activity and a proper diet. Other studies indicate that the percentage of pregnant women leading a mainly passive lifestyle during the pandemic was $79 \%$, with only $23 \%$ of those who were active following guidelines for physical activity during pregnancy (before the pandemic, this percentage was $47 \%$ ). Fear of leaving home due to the prevalence of COVID-19 was the most commonly reported reason for a decline in activity [56]. Muhaidat et al. [57] noted that during pregnancy as much as 35.91\% of women decreased their physical activity compared to the period before the lockdown. There were $6.04 \%$ of women who maintained their current level of activity, while $2.01 \%$ increased it. A reduction of physical activity during the pandemic in pregnant women (regardless of the trimester) was also noted in studies by Hashim et al. [58] — of all surveyed women, 53.6\% reduced time spent on physical activity and only $13.8 \%$ increased it. In turn, Hu et al. [59] showed that during the early stage of the pandemic, more nonpregnant women reduced their physical activity compared to pregnant women (50.0\% vs 40.4\%). Nascimento el al. [50] indicated that higher education, primiparity, work, medical private care, pregnancy planning, pre-pregnancy activity and exercise information/tips had a significant impact on the level of physical activity in pregnancy.

Pregnancy should be a time of emotional well-being in a woman's life; unfortunately, for many women it is a time full of fear, anxiety, increased stress and even the development of depressive disorders [60]. Among the participants in our study, we observed a negative correlation between perceived stress levels and life satisfaction. In addition, most women in each group (over 60\%) reported high satisfaction with their lives. However, our study showed that regardless of the period of delivery, the level of overall stress experienced by women remained unchanged (prepandemic group Me: 18.0, Q1-Q3: 13.0-22.0 points; COVID 1 group Me: 17.0, Q1-Q3: 13.0-22.0 points; and COVID 2 group Me: 17.0, Q1-Q3: 13.0-22.0 points). In addition, the percentages of women with low, medium and high stress were similar when comparing them within and between groups. In contrast, PuertasGonzalez et al. observed that women who were pregnant during the pandemic had a higher level of perceived stress than women who were pregnant before the pandemic [61]. Available studies indicate that women who consider COVID-19 as a stress factor experience higher levels of stress than pregnant women who do not link it to their current situation [8]. Stepowicz et al. [25] showed that levels of stress and anxiety in pregnant or postpartum women during the pandemic were moderate to high. In other studies conducted in Poland during the pandemic, a moderate and positive relationship among women was observed between perceived stress, fear of COVID-19 and fear of childbirth [24]. Ilska et al. [26] noted that during the second wave of the pandemic, almost $38.5 \%$ of pregnant women reported high preparedness stress and $26 \%$ reported high perinatal infection stress. In turn, Jiang et al. [62] observed that in China in February 2020 the prevalence of perceived stress in pregnancy was $89.1 \%$. Other studies also show that during the pandemic, women report high levels of stress associated with both pregnancy and the COVID-19 pandemic [63]. According to a review by Campos-Garzón et al. [64] the level of stress experienced by 
pregnant women is influenced by feelings of loneliness and fear of infection. Moreover, stress has been recognized as a predictor of anxiety and depression symptoms related to COVID-19. Meta-analysis performed by Demissie et al. [65] estimates that as much as $56 \%$ of pregnant and breastfeeding women experienced stress during the pandemic. The surveyed women also had depressive disorders $(27 \%)$, anxiety ( $33 \%)$, sleep problems $(34 \%)$ and social dysfunction $(24 \%)$. Other studies have also shown that at the beginning of the pandemic, women's anxiety about their own, their child's and their partner's health increased drastically. Similar changes were also noted in the partners of pregnant women [66]. In turn, Çiler Eren et al. [67] observed that a diagnosis of COVID-19 in a pregnant family resulted in high scores in all cases, yet had no effect on the overall scores for depression, stress and anxiety. Nevertheless, there are many studies which show that pregnant women were exposed to stressful situations before the pandemic was announced [68-72]. Low socioeconomic status, lack of support from family, violence from partners and obstetric factors including unplanned pregnancy have been identified as socio-demographic factors having significant impacts on negative mental health changes in pregnant women [73].

\section{Strengths and Limitations}

There are several strengths and limitations of this study. The strength of this study comes from surveying women during different stages of the pandemic; this provides us a look at whether or not the period of the pandemic (which differed in knowledge about the virus, restrictions and vaccination possibilities) had an impact on particular aspects of women's behavior. One limitation of this study is that women in the prepandemic group were tested from December 2019 to March 2020 when no pandemic state was yet declared, even as the virus was already present in China and in other countries. Moreover, we only examined women who were patients in Cracow hospitals. The introduced restrictions, numbers of cases and vaccinations differed between particular areas in Poland, therefore we cannot compare our results to the general population of women in the perinatal period. Moreover, we assessed levels of activity, perceived stress and satisfaction with life using selfreport questionnaires which may bias the obtained data. Therefore, longitudinal studies with multiple points of data collection are needed to better understand patterns of change in the psychological states of women. In addition, testing should be extended throughout pregnancy and the postpartum period.

\section{Conclusions}

It was observed that women in the third trimester of pregnancy during the pandemic reduced their levels of energy spent on total physical activity compared to pregnant participants before the pandemic. The scope and types of activities may have been influenced by the introduced restrictions that limited, for example, access to parks, forests and fitness clubs. The introduction of restrictions related to spending free time outside the home, learning and remote work could cause changes in the performance of household duties by individual household members. In the research it was noted that women who were pregnant in the later stage of the pandemic spent significantly less energy on home activities. Women who gave birth in 2020 (COVID 1 group) also reported significantly reduced levels of activity related to movement. There were no significant changes in the levels of life satisfaction and perceived stress in late pregnancy and early postpartum among the examined patient groups. Most women (regardless of the period of the study) had a high level of life satisfaction. Both before and during the pandemic (early and late period), the distribution of the level of perceived stress was similar. It was also noted in all groups that as life satisfaction increased, stress decreased. Nevertheless, the strongest correlation between stress and life satisfaction was found among women giving birth before the pandemic. The individual parameters of stress and life satisfaction affected the levels of certain physical activity components in the surveyed women. 
Author Contributions: Conceptualization, A.I.M.-B.; methodology, A.I.M.-B.; validation, A.I.M.-B.; formal analysis, A.I.M.-B., D.K.-B. and A.M.; investigation, D.K.-B.; resources, A.I.M.-B. and D.K.-B.; data curation, D.K.-B.; writing-original draft preparation, A.I.M.-B. and D.K.-B.; writing-review and editing, A.I.M.-B. and D.K.-B.; visualization, D.K.-B.; supervision, A.I.M.-B.; project administration, A.I.M.-B. (D.K.-B. 55\%; A.I.M.-B. 40\%; A.M. 5\%). All authors have read and agreed to the published version of the manuscript.

Funding: This research was funded by Jagiellonian University, grant number N43/DBS/000116.

Institutional Review Board Statement: The study was conducted in accordance with the Declaration of Helsinki and approved by the Ethics Committee of Jagiellonian University (Opinion No. 1072.6120.251.2019 of 26 October 2019).

Informed Consent Statement: Informed consent was obtained from all subjects involved in the study.

Data Availability Statement: The data underlying this article will be shared on reasonable request to the corresponding author.

Conflicts of Interest: The authors declare no conflict of interest.

\section{References}

1. Bjelica, A.; Cetkovic, N.; Trninic-Pjevic, A.; Mladenović-Segedi, L. The phenomenon of pregnancy-A psychological view. Ginekol. Pol. 2018, 89, 102-106. [CrossRef] [PubMed]

2. Rodriguez-Ayllon, M.; Acosta-Manzano, P.; Coll-Risco, I.; Romero-Gallardo, L.; Borges-Cosic, M.; Estévez-López, F.; Aparicio, V.A. Associations of physical activity, sedentary time, and physical fitness with mental health during pregnancy: The GESTAFIT project. J. Sport Health Sci. 2021, 10, 379-386. [CrossRef] [PubMed]

3. Feduniw, S.; Modzelewski, J.; Kajdy, A.; Sys, D.; Kwiatkowski, S.; Makomaska-Szaroszyk, E.; Rabijewski, M. Anxiety of pregnant women in time of catastrophic events, including COVID-19 pandemic: A systematic review and meta-analysis. J. Psychosom. Obstet. Gynecol. 2021, 11, 1-11. [CrossRef]

4. Salehi, L.; Rahimzadeh, M.; Molaei, E.; Zaheri, H.; Esmaelzadeh-Saeieh, S. The relationship among fear and anxiety of COVID-19, pregnancy experience, and mental health disorder in pregnant women: A structural equation model. Brain Behav. 2020, 10 , e01835. [CrossRef]

5. Salari, N.; Hosseinian-Far, A.; Jalali, R.; Vaisi-Raygani, A.; Rasoulpoor, S.; Mohammadi, M.; Rasoulpoor, S.; Khaledi-Paveh, B. Prevalence of stress, anxiety, depression among the general population during the COVID-19 pandemic: A systematic review and meta-analysis. Glob. Health 2020, 16, 57. [CrossRef] [PubMed]

6. Ostacoli, L.; Cosma, S.; Bevilacqua, F.; Berchialla, P.; Bovetti, M.; Carosso, A.R.; Malandrone, F.; Carletto, S.; Benedetto, C. Psychosocial factors associated with postpartum psychological distress during the COVID-19 pandemic: A cross-sectional study. BMC Pregnancy Childbirth 2020, 20, 703. [CrossRef]

7. Mazur-Bialy, A.I.; Kołomańska-Bogucka, D.; Tim, S.; Opławski, M. Pregnancy and Childbirth in the COVID-19 Era-The Course of Disease and Maternal-Fetal Transmission. J. Clin. Med. 2020, 9, 3749. [CrossRef]

8. Zilver, S.J.M.; Broekman, B.F.P.; Hendrix, Y.M.G.A.; de Leeuw, R.A.; Mentzel, S.V.; van Pampus, M.G.; de Groot, C.J.M. Stress, anxiety and depression in 1466 pregnant women during and before the COVID-19 pandemic: A Dutch cohort study. J. Psychosom. Obstet. Gynecol. 2021, 42, 108-114. [CrossRef] [PubMed]

9. World Health Organization. Coronavirus Disease (COVID-19): Pregnancy and Childbirth. Available online: https:/ /www.who. int/news-room/q-a-detail/coronavirus-disease-covid-19-pregnancy-and-childbirth (accessed on 16 December 2020).

10. Magnus, M.C.; Havdahl, A.; Morken, N.-H.; Wensaas, K.-A.; Wilcox, A.J.; Haberg, S.E. Risk of miscarriage in women with psychiatric disorders. Br. J. Psychiatry 2021, 219, 501-506. [CrossRef] [PubMed]

11. Staneva, A.; Bogossian, F.; Pritchard, M.; Wittkowski, A. The effects of maternal depression, anxiety, and perceived stress during pregnancy on preterm birth: A systematic review. Women Birth 2015, 28, 179-193. [CrossRef]

12. Grote, N.K.; Bridge, J.A.; Gavin, A.R.; Melville, J.L.; Iyengar, S.; Katon, W.J. A Meta-analysis of Depression During Pregnancy and the Risk of Preterm Birth, Low Birth Weight, and Intrauterine Growth Restriction. Arch. Gen. Psychiatry 2010, 67, 1012-1024. [CrossRef]

13. Hasanjanzadeh, P.; Faramarzi, M. Relationship between Maternal General and Specific-Pregnancy Stress, Anxiety, and Depression Symptoms and Pregnancy Outcome. J. Clin. Diagn. Res. 2017, 11, VC04-VC07. [CrossRef] [PubMed]

14. Ayaz, R.; Hocaoğlu, M.; Günay, T.; Yardımcı, O.D.; Turgut, A.; Karateke, A. Anxiety and depression symptoms in the same pregnant women before and during the COVID-19 pandemic. J. Périnat. Med. 2020, 48, 965-970. [CrossRef] [PubMed]

15. Dennis, C.-L.; Falah-Hassani, K.; Shiri, R. Prevalence of antenatal and postnatal anxiety: Systematic review and meta-analysis. Br. J. Psychiatry 2017, 210, 315-323. [CrossRef] [PubMed]

16. Sun, F.; Zhu, J.; Tao, H.; Ma, Y.; Jin, W. A systematic review involving 11,187 participants evaluating the impact of COVID-19 on anxiety and depression in pregnant women. J. Psychosom. Obstet. Gynecol. 2019, 42, 91-99. [CrossRef] [PubMed] 
17. Mappa, I.; Distefano, F.A.; Rizzo, G. Effects of coronavirus 19 pandemic on maternal anxiety during pregnancy: A prospectic observational study. J. Périnat. Med. 2020, 48, 545-550. [CrossRef]

18. Ng, Q.J.; Koh, K.M.; Tagore, S.; Mathur, M. Perception and feelings of antenatal women during COVID-19 pandemic: A cross-sectional survey. Ann. Acad. Med. Singap. 2020, 49, 543-552. [CrossRef] [PubMed]

19. Limbers, C.A.; McCollum, C.; Greenwood, E. Physical activity moderates the association between parenting stress and quality of life in working mothers during the COVID-19 pandemic. Ment. Health Phys. Act. 2020, 19. [CrossRef]

20. Kolomanska-Bogucka, D.; Mazur-Bialy, A.I. Physical activity and depressive disorders in pregnant women-A systematic review. Medicina 2019, 55, 212. [CrossRef]

21. Kolomanska-Bogucka, D.; Mazur-Bialy, A.I. Physical activity and the occurrence of postnatal depression-A systematic review. Medicina 2019, 55, 560. [CrossRef]

22. The American College of Obstetricians and Gynecologists. Exercise during Pregnancy. Available online: https://www.acog.org/ womens-health/faqs/exercise-during-pregnancy (accessed on 12 December 2021).

23. Sahin, B.M.; Kabakci, E.N. The experiences of pregnant women during the COVID-19 pandemic in Turkey: A qualitative study. Women Birth 2020, 34, 162-169. [CrossRef]

24. Dymecka, J.; Gerymski, R.; Iszczuk, A.; Bidzan, M. Fear of coronavirus, stress and fear of childbirth in Polish pregnant women during the COVID-19 pandemic. Int. J. Environ. Res. Public Health 2021, 18, 13111. [CrossRef] [PubMed]

25. Stepowicz, A.; Wencka, B.; Bienkiewicz, J.; Horzelski, W.; Grzesiak, M. Stress and anxiety levels in pregnant and post-partum women during the COVID-19 pandemic. Int. J. Environ. Res. Public Health 2020, 17, 9450. [CrossRef] [PubMed]

26. Ilska, M.; Kołodziej-Zaleska, A.; Brandt-Salmeri, A.; Preis, H.; Lobel, M. Pandemic stress and its correlates among pregnant women during the second wave of COVID-19 in Poland. Int. J. Environ. Res. Public Health 2021, 18, 11140. [CrossRef] [PubMed]

27. Janik, K.; Cwalina, U.; Iwanowicz-Palus, G.; Cybulski, M. An assessment of the level of COVID-19 anxiety among pregnant women in Poland: A cross-sectional study. J. Clin. Med. 2021, 10, 5869. [CrossRef] [PubMed]

28. Chasan-Taber, L.; Schmidt, M.D.; Roberts, D.E.; Hosmer, D.; Markenson, G.; Freedson, P.S. Development and validation of a pregnancy physical activity questionnaire. Med. Sci. Sports Exerc. 2004, 36, 1750-1760. [CrossRef] [PubMed]

29. Krzepota, J.; Sadowska, D. Pregnancy physical activity questionnaire-Polish version (PPAQ-PL). Med. Ogólna Nauk. Zdrowiu 2017, 23, 100-106. [CrossRef]

30. Krzepota, J.; Sadowska, D.; Sempolska, K.; Pelczar, M. Measuring physical activity during pregnancy-Cultural adaptation of the pregnancy physical activity questionnaire (PPAQ) and assessment of its reliability in Polish conditions. Ann. Agric. Environ. Med. 2017, 24, 640-643. [CrossRef]

31. Juczynski, Z. Narzędzia Pomiaru w Promocji i Psychologii Zdrowia; Wydawnictwo Pracownia Testów Psychologicznych Polskiego Towarzystwa Psychologicznego: Warszawa, Poland, 2012; pp. 128-132.

32. Pavot, W.; Diener, E. Review of the Satisfaction with Life Scale. Assessing Well-Being; Social Indicators Research Series; Springer: Dordrecht, The Netherlands, 2009; pp. 101-117. [CrossRef]

33. Ramiro-Cortijo, D.; de la Calle, M.; Benitez, V.; Gila-Diaz, A.; Moreno-Jiménez, B.; Arribas, S.M.; Garrosa, E. Maternal Psychological and Biological Factors Associated to Gestational Complications. J. Pers. Med. 2021, 11, 183. [CrossRef] [PubMed]

34. Aasheim, V.; Waldenström, U.; Rasmussen, S.; Espehaug, B.; Schytt, E. Satisfaction with life during pregnancy and early motherhood in first-time mothers of advanced age: A population-based longitudinal study. BMC Pregnancy Childbirth 2014, 14, 86. [CrossRef]

35. Skurzak, A.; Zarajczyk, M.; Iwanowicz-Palus, G.; Korzynska-Piętas, M.; Lewicka, M.; Wiktor, H. Life satisfaction of the pregnant women. Pielegniarstwo XXI Wieku/Nurs. 21st Century 2019, 4, 207-213. [CrossRef]

36. Branecka-Wozniak, D.; Wojcik, A.; Blazejewska-Jaskowiak, J.; Kurzawa, R. Sexual and life satisfaction of pregnant women. Int. J. Environ. Res. Public Health 2020, 17, 5894. [CrossRef] [PubMed]

37. Badr, H.A.; Zauszniewski, J.A.; Quinn Griffin, M.; Burant, C.J.; Przeworski, A.; Almutairi, W.M.; Alsharif, F.H. Effects of postpartum fatigue and depressive cognitions on life satisfaction and quality of life in arab postpartum women: The intervening role of resourcefulness. Nurs. Rep. 2021, 11, 84-94. [CrossRef] [PubMed]

38. Juczynski, Z.; Oginska-Bulik, N. Narzędzia Pomiaru Stresu i Radzenia Sobie ze Stresem; Wydawnictwo Pracownia Testów Psychologicznych Polskiego Towarzystwa Psychologicznego: Warszawa, Poland, 2012; pp. 14-22.

39. Cohen, S.; Kamarck, T.; Mermelstein, R. A global measure of perceived stress. J. Health Soc. Behav. 1983, 24, 385-396. [CrossRef] [PubMed]

40. Szumilewicz, A.; Wojtyla, A.; Zarebska, A.; Drobnik-Kozakiewicz, I.; Sawczyn, M.; Kwitniewska, A. Influence of prenatal physical activity on the course of labour and delivery according to the new Polish standard for perinatal care. Ann. Agric. Environ. Med. 2013, 20, 380-389. [PubMed]

41. Syed, H.; Slayman, T.; Thoma, K.D. ACOG committee opinion no. 804: Physical activity and exercise during pregnancy and the postpartum period. Obstet. Gynecol. 2021, 137, 375-376. [CrossRef] [PubMed]

42. Wojtyla, A.; Kapka-Skrzypczak, L.; Paprzycki, P.; Skrzypczak, M.; Bilinski, P. Epidemiological studies in Poland on effect of physical activity of pregnant women on the health of offspring and future generations-Adaptation of the hypothesis development origin of health and diseases. Ann. Agric. Environ. Med. 2012, 19, 315-326. [PubMed]

43. Ferrari, N.; Joisten, C. Impact of physical activity on course and outcome of pregnancy from pre- to postnatal. Eur. J. Clin. Nutr. 2021, 75, 1698-1709. [CrossRef] 
44. Coussons-Read, M.E. Effects of prenatal stress on pregnancy and human development: Mechanisms and pathways. Obstet. Med. 2013, 6, 52-57. [CrossRef]

45. Brooks, S.K.; Weston, D.; Greenberg, N. Psychological impact of infectious disease outbreaks on pregnant women: Rapid evidence review. Public Health 2020, 189, 26-36. [CrossRef] [PubMed]

46. Davenport, M.H.; Meyer, S.; Meah, V.L.; Strynadka, M.C.; Khurana, R. Moms are not ok: COVID-19 and maternal mental health. Front. Glob. Women Health 2020, 1, 1-6. [CrossRef] [PubMed]

47. Wojtyla, C.; Ciebiera, M.; Wojtyła-Buciora, P.; Janaszczyk, A.; Brzęcka, P.; Wojtyla, A. Physical activity patterns in third trimester of pregnancy-Use of pregnancy physical activity questionnaire in Poland. Ann. Agric. Environ. Med. 2020, 27, 388-393. [CrossRef] [PubMed]

48. Krzepota, J.; Sadowska, D.; Biernat, E. Relationships between physical activity and quality of life in pregnant women in the second and third trimester. Int. J. Environ. Res. Public Health 2018, 15, 2745. [CrossRef] [PubMed]

49. Schmidt, T.; Heilmann, T.; Savelsberg, L.; Maass, N.; Weisser, B.; Eckmann-Scholz, C. Physical exercise during pregnancy-How active are pregnant women in Germany and how well informed? Geburtshilfe Frauenheilkd. 2017, 77, 508-515. [CrossRef] [PubMed]

50. Nascimento, S.L.; Surita, F.G.; Godoy, A.C.; Kasawara, K.T.; Morais, S.S. Physical activity patterns and factors related to exercise during pregnancy: A cross sectional study. PLoS ONE 2015, 10, e0128953. [CrossRef]

51. Meaney, S.; Leitao, S.; Olander, E.K.; Pope, J.; Matvienko-Sikar, K. The impact of COVID-19 on pregnant womens' experiences and perceptions of antenatal maternity care, social support, and stress-reduction strategies. Women Birth, 2021; in press. [CrossRef] [PubMed]

52. Bivia-Roig, G.; La Rosa, V.L.; Gomez-Tebar, M.; Serrano-Raya, L.; Amer-Cuenca, J.J.; Caruso, S.; Commodari, E.; Barrasa-Shaw, A.; Lison, J.F. Analysis of the impact of the confinement resulting from COVID-19 on the lifestyle and psychological wellbeing of spanish pregnant women: An internet-based cross-sectional survey. Int. J. Environ. Res. Public Health. 2020, 17, 5933. [CrossRef]

53. Lebel, C.; MacKinnon, A.; Bagshawe, M.; Tomfohr-Madsen, L.; Giesbrecht, G. Elevated depression and anxiety symptoms among pregnant individuals during the COVID-19 pandemic. J. Affect. Disord. 2020, 277, 5-13. [CrossRef]

54. Hori, N.; Shiraishi, M.; Harada, R.; Kurashima, Y. Association of lifestyle changes due to the COVID-19 pandemic with nutrient intake and physical activity levels during pregnancy in Japan. Nutrients 2021, 13, 3799. [CrossRef]

55. Kumari, A.; Ranjan, P.; Sharma, K.A.; Sahu, A.; Bharti, J.; Zangmo, R.; Bhatla, N. Impact of COVID-19 on psychosocial functioning of peripartum women: A qualitative study comprising focus group discussions and in-depth interviews. Int. J. Gynaecol. Obstet. 2021, 152, 321-327. [CrossRef]

56. Hillyard, M.; Sinclair, M.; Murphy, M.; Casson, K.; Mulligan, C. The impact of COVID-19 on the physical activity and sedentary behaviour levels of pregnant women with gestational diabetes. PLoS ONE 2021, 16, e0254364. [CrossRef] [PubMed]

57. Muhaidat, N.; Fram, K.; Thekrallah, F.; Qatawneh, A.; Al-Btoush, A. Pregnancy during COVID-19 outbreak: The impact of lockdown in a middle-income country on antenatal healthcare and wellbeing. Int. J. Womens Health 2020, 12, 1065-1073. [CrossRef]

58. Hashim, M.; Coussa, A.; Dhaheri, A.S.A.; Marzouqi, A.A.; Cheaib, S.; Salame, A.; Jamous, D.O.A.; Naja, F.; Hasan, H.; Stojanovska, L.; et al. Impact of coronavirus 2019 on mental health and lifestyle adaptations of pregnant women in the United Arab Emirates: A cross-sectional study. BMC Pregnancy Childbirth 2021, 21, 515. [CrossRef] [PubMed]

59. Hu, W.S.; Lu, S.; Xu, M.Y.; Zhou, M.C.; Yuan, Z.M.; Deng, Y.Y. Behavioral responses of pregnant women to the early stage of COVID-19 pandemic in the network era in China: Online questionnaire study. Asian Nurs. Res. 2021, 15, 215-221. [CrossRef]

60. Priya, A.; Chaturvedi, S.; Bhasin, S.K.; Bhatia, M.S.; Radhakrishnan, G. Depression, anxiety and stress among pregnant women: A community-based study. Indian J. Psychiatry 2018, 60, 151-152. [CrossRef] [PubMed]

61. Puertas-Gonzalez, J.A.; Marino-Narvaez, C.; Peralta-Ramirez, M.I.; Romero-Gonzalez, B. The psychological impact of the COVID-19 pandemic on pregnant women. Psychiatry Res. 2021, 301, 113978. [CrossRef] [PubMed]

62. Jiang, H.; Jin, L.; Qian, X.; Xiong, X.; La, X.; Chen, W.; Yang, X.; Yang, F.; Zhang, X.; Abudukelimu, N.; et al. Maternal mental health status and approaches for accessing antenatal care information during the COVID-19 epidemic in China: Cross-sectional study. J. Med. Internet Res. 2021, 23, e18722. [CrossRef]

63. Pope, J.; Olander, E.K.; Leitao, S.; Meaney, S.; Matvienko-Sikar, K. Prenatal stress, health, and health behaviours during the COVID-19 pandemic: An international survey. Women Birth, 2021; in press. [CrossRef] [PubMed]

64. Campos-Garzon, C.; Riquelme-Gallego, B.; de la Torre-Luque, A.; Caparros-Gonzalez, R.A. Psychological impact of the COVID-19 pandemic on pregnant women: A scoping review. Behav. Sci. 2021, 11, 181. [CrossRef]

65. Demissie, D.B.; Bitew, Z.W. Mental health effect of COVID-19 pandemic among women who are pregnant and/or lactating: A systematic review and meta-analysis. SAGE Open Med. 2021, 9, 20503121211026195. [CrossRef] [PubMed]

66. Naurin, E.; Markstedt, E.; Stolle, D.; Enstrom, D.; Wallin, A.; Andreasson, I.; Attebo, B.; Eriksson, O.; Martinsson, K.; Elden, H.; et al. Pregnant under the pressure of a pandemic: A large-scale longitudinal survey before and during the COVID-19 outbreak. Eur. J. Public Health 2021, 31, 7-13. [CrossRef] [PubMed]

67. Eren, E.C.; Şanlı, S.G. The effect of COVID-19 pandemic on depression, anxiety and stress levels of pregnant women. Bagcilar Med. Bull. 2021, 6, 306-313. [CrossRef]

68. Pantha, S.; Hayes, B.; Yadav, B.K.; Sharma, P.; Shrestha, A.; Gartoulla, P. Prevalence of stress among pregnant women attending antenatal care in a tertiary maternity hospital in Kathmandu. J. Women Health Care 2014, 3, 183. [CrossRef]

69. Engidaw, N.A.; Mekonnen, A.G.; Amogne, F.K. Perceived stress and its associated factors among pregnant women in bale zone hospitals, Southeast Ethiopia: A cross-sectional study. BMC Res. Notes 2019, 12, 356. [CrossRef] [PubMed] 
70. Thongsomboon, W.; Kaewkiattikun, K.; Kerdcharoen, N. Perceived stress and associated factors among pregnant women attending antenatal care in urban Thailand. Psychol. Res. Behav. Manag. 2020, 13, 1115-1122. [CrossRef] [PubMed]

71. Ahmed, A.E.; Albalawi, A.N.; Alshehri, A.A.; AlBlaihed, R.M.; Alsalamah, M.A. Stress and its predictors in pregnant women: A study in Saudi Arabia. Psychol. Res. Behav. Manag. 2017, 10, 97-102. [CrossRef]

72. Iranzad, I.; Bani, S.; Hasanpour, S.; Mohammadalizadeh, S.; Mirghafourvand, M. Perceived social support and stress among pregnant women at health centers of Iran- Tabriz. J. Caring Sci. 2014, 3, 287-295. [CrossRef]

73. Nagandla, K.; Nalliah, S.; Yin, L.; Majeed, Z.; Ismail, M.; Zubaidah, S.; Ragavan, U.; Krishnan, S. Prevalence and associated risk 430 factors of depression, anxiety and stress in pregnancy. Int. J. Reprod. Contracept. Obstet. Gynecol. 2016, 5, 2380-2388. [CrossRef] 